\title{
Espacio y tiempo como base para una lectura sociocrítica de Gracias por el fuego de Mario Benedetti
}

JACQUES SOUBEYROUX

Universidad de Montpellier

Espacio y tiempo parecen ser dos dimensiones ineludibles de cualquier texto narrativo. Sin embargo, el tratamiento que la crítica narratológica de Genette ha hecho del uno y del otro es muy distinto, a veces opuesto. Por una parte, la narratología ha desarrollado y precisado, de manera pertinente y provechosa, la teoría de la temporalidad, haciendo de ésta una dimensión esencial de la novela. En cambio, el espacio en que se sitúa la historia ha sido totalmente eliminado, borrado, sustituido en el mejor de los casos por: «La spatialité primaire, élémentaire, le langage lui-même, [...] la spatialité du langage considéré dans son système implicite accentué dans l'oeuvre littéraire par l'emploi de texte écrit», opuesta a «des demeures, des paysages, des lieux» '. Muy reveladora de esta actitud es la siguiente afirmación de Genette: «Je peux fort bien raconter une histoire sans préciser le lieu où elle se passe, tandis qu'il m'est presque impossible de ne pas la situer dans le temps par rapport à mon acte narratif ${ }^{2}$.

1 Genette, «La littérature et l'espace», Figures II, Paris, Seuil, 1969, p. 44.

2 Genette, «Le discours du récit», Figures III, Paris, Seuil, 1972, p. 228. 
Esta frase opone dos categorías esenciales del texto novelesco, estrechamente vinculadas, la temporalidad y la narración, a una tercera categoría que no parece tener relación con las dos primeras y por lo tanto no ser pertinente para la crítica, el espacio.

En contra de esta posición, propondré como hipótesis de trabajo que:

1. cualquier elemento de un discurso narrativo es significante;

2. todas las categorías del relato, como el espacio, el tiempo, la narración, los personajes, son solidarias del conjunto del tejido textual $\mathrm{y}$, por lo tanto, igualmente pertinentes;

3. el análisis de estas categorías ha de permitir, más allá de una simple descripción narratológica, alcanzar las estructuras profundas del texto, y proponer una lectura crítica de su contenido ideológico.

Es lo que trataré de mostrar con las categorías del espacio y del tiempo aplicadas a la novela del escritor uruguayo Mario Benedetti, Gracias por el fuego ${ }^{3}$.

Este estudio utilizará las propuestas metodológicas de Henri Mitterand ${ }^{4}$ para el análisis del espacio, y las de Gérard Genette para el del tiempo, pero dentro de una perspectiva sociocrítica, a partir de los presupuestos teóricos del C.E.R.S. (Centro de Estudios y de Investigación Sociocrítica) de Montpellier, tales como han sido definidos por Edmond Cros ${ }^{5}$.

\section{El espacio narrativo en Gracias por el fuego}

Siguiendo el método puesto a punto por Mitterand a propósito de la novela breve de Balzac Ferragus, y que he vuelto a definir y tratado de precisar para aplicarlo a la novela hispanoamericana ${ }^{6}$, estudiaré tres

3 Benedetti, Gracias por el fuego (escrita en 1963, primera edición Montevideo, 1965). Todas las citas siguientes remiten a la edición Alfaguara, Madrid, 1983.

4 Mitterand, «Le lieu et le sens: l'espace parisien dans Ferragus de Balzac», Le discours du roman, Paris, P.U.F., 1980.

5 E. Cros, Théorie et pratiques sociocritiques, Montpellier, C.E.R.S., Université Paul Valéry, 1983.

6 Véanse mis artículos «Pour une étude de l'espace dans le roman: propositions méthodologiques et application à La ciudad y los perros de Vargas Llosa» y «L'espace dans María de Jorge Isaacs», Imprévue, Montpellier, C. E. R. S., 1985/1. 
niveles del discurso del texto sobre el espacio: la topografía mimética, la toposemia funcional y el simbolismo ideológico.

\subsection{Topografía mimética}

Un inventario de los lugares en que se desarrolla la historia revela en seguida el carácter mimético muy marcado del espacio en Gracias por el fuego.

Las primeras páginas de la novela (13-14) son una descripción, que una crítica tradicional calificaría de reálista, de una calle de Broadway: un narrador anónimo, ausente, omnisciente, nos muestra el exterior y el interior de las casas, la suciedad y la pobreza, y nos hace penetrar en un restaurante para escuchar las conversaciones que se desarrollan en él. Ningún detalle es gratuito en este relato donde se revela ya claramente la doble función didáctica e ideológica del narrador, pero lo esencial es la ilusión realista así creada, el efecto de realidad ${ }^{7}$. Como escribe Mitterand ${ }^{8}$ : «C'est le lieu qui fonde le récit, parce que l'événement a besoin d'un ubi autant que d'un quid ou d'un quando; c'est le lieu que donne à la fiction !'apparence de la vérité».

A este incipit neoyorkino se opone el espacio de los demás capítulos (2 a 15) de la novela, que nos sitúa en diferentes lugares de Uruguay (Montevideo, Cuareim, Paysandú, Tecuarembo, Punta del Este) o en Buenos Aires. Lo esencial de la acción pasa en Montevideo aunque el nombre de la capital uruguaya no está mencionado ni una vez en estos capítulos. Los principales lugares que se pueden identificar son los siguientes:

-La Rambla (unas dieciocho ocurrencias), que Eduardo Nogareda define así ${ }^{9}$ : "avenida que costea las playas donde suelen vivir las familias adineradas de Montevideo». En efecto, al hablar de la Rambla, el texto alude varias veces al mar: «un cliente me advirtió que en la Rambla las olas salpicaban mucho» (p. 171), «en la tarde, cuando regreso por la Rambla, me conmueve este murallón de grandes edificios que dan sombra a la playa y la cubren de una falsa melancolía (p. 240).

7 R. Barthes, «L'effet de réel», Communications, 11, 1968, p. 84-89.

8 Mitterand, p. 194.

9 M. Benedetti, La Tregua, ed. E. Nogareda, Madrid, Cátedra, 1978, p. 245; nota. 
- Las calles céntricas: Dieciocho, Río Bravo (p. 184), San José (p. 223), etc...

-Diferentes barrios populares (el Paso Molino, p. 26) o residenciales (Punta Carretas, p. 72, Punta Gorda, p. 174) de la ciudad.

-El palacio Salvo, uno de los rascacielos de Montevideo (p. 30).

-El Águila, uno de los más famosos restaurantes de la capital (p. $80)$.

-El viejo Tupí (p. 118) que era una «famosa cafetería típica montevideana desaparecida ya hace varios años. Estaba situada junto a la Plaza Independencia. Su nombre completo es Tupí Namba» ${ }^{10}$.

A pesar de no estar nombrado Montevideo, el carácter referencial del texto es evidente: los personajes se mueven por unos lugares bien conocidos por cualquier montevideano, y que el lector de otras novelas de Mario Benedetti, como La Tregua, identifica en seguida. Esta referencialidad constituye, al mismo tiempo, un procedimiento de codificación ideológica: el hecho que el protagonista de la novela, Ramón $\mathrm{Bu}-$ diño, viva en un estudio en Punta Gorda lo clasifica en seguida en la burguesía montevideana. La alusión recurrente a la Rambla tiene el mismo valor ${ }^{11}$.

Estas alusiones están confirmadas por las descripciones de los lugares de la acción:

-El despacho del padre, Edmundo Budiño, en «la principal avenida» (p. 46).

-El estudio de Punta Gorda, «con buena biblioteca y vista al mar» (p. 174).

Y por los papeles profesionales atribuidos a los actores: Edmundo Budiño es director de un diario y una fábrica; su hijo Ramón tiene una agencia de viajes, etc...,

Gracias por el fuego aparece así como una novela sobrecodificada al nivel sociológico: toda la historia pasa en los medios burgueses de

10 La Tregua, p. 198.

11 En La Tregua (p. 245) podemos leer: «No quiero un Dios que me brinde todo hecho, como podría hacer uno de esos prósperos padres de la Rambla, podridos en plata, con su hijo pituco e inservible. Eso sí que no.» 
la capital uruguaya, y las referencias a la noción de clase social son frecuentes («los tabúes de mi clase», «los hombres de mi clase», p. 271). Por referencia a un contexto extratextual auténtico, el espacio inscribe así en el texto unos valores ideológicos y unas referencias sociales que orientan fuertemente el desarrollo de la historia, como veremos estudiando la toposemia funcional.

\subsection{Toposemia funcional}

El espacio novelesco no significa sólo por su grado de mimetismo, su referencialidad. Los diferentes lugares de la acción constituyen unos verdaderos actores dotados de auténticas funciones en la acción. La toposemia funcional consistirá en el estudio de estas funciones, de los ejes semánticos a los que corresponden en los personajes para orientarnos hacia su significación simbólica e ideológica.

\subsubsection{El espacio de Ramón Budiño}

Mientras la mayoría de los personajes (en particular los personajes femeninos, como Susana, Gloria o la secretaria de Ramón) evolucionan siempre en un mismo lugar, Ramón Budiño es un personaje dinámico, que va de un lugar a otro, entrando así en contacto con los demás personajes.

En los episodios del pasado (niñez y juventud), vemos a Ramón evolucionando en diferentes lugares, interiores y exteriores:

- La casa familiar, en particular su habitación, la casa de la tía Olga (p. 55), una tienda de juguetes (p. 48), la iglesia (p. 72), el colegio (p. 81).

-La calle (p. 50), el Parque (p. 64), la playa de Portezuelo (p. 105), la vía ferroviaria cerca de la casa de la húngara (p. 148).

Podemos subrayar en seguida la oposición entre unos lugares cerrados que corresponden a tres instancias que Louis Althusser califica de «Aparatos Ideológicos de Estado» ${ }^{12}$, y unos lugares abiertos repre- 
sentativos de la libertad festiva y sexual del protagonista (el carnaval, los primeros amores). Si la casa familiar aparece al principio como un lugar feliz, en que el niño está protegido (bondad, generosidad del padre, p. 48, y de la madre, p. 63), pronto se va convirtiendo en un lugar peligroso (la oscuridad, la amenaza de la salida al colegio, la muerte del primo Víctor) y represivo (escena detrás de la mampara en que el padre pega a la madre). Este mismo carácter represivo es evidente en la presentación del colegio alemán (p. 81-85) y de la religión (p. 73, p. 272). Una primera característica digna de ser notada es el carácter represivo que tienen en el texto las tres instancias entre las que evoluciona Ramón niño: la familia, la educación y la religión.

En el presente, los principales lugares entre los cuales se desplaza Ramón son los siguientes:

- Su estudio de Punta Gorda.

- La agencia de viajes.

-El despacho de su padre.

- La casa de la tía Olga.

- La casa de su hermano Hugo.

-El apartamento de las Tres Jotas.

O sea, seis lugares cerrados. Pero, entre esos lugares cerrados, numerosas secuencias tienen como escenario las calles céntricas, que Ramón recorre a pie, y sobre todo la Rambla, ese lugar de transición casi ineludible, a orillas del mar, que Ramón toma para ir del centro de la ciudad al apartamento familiar. Precisemos la significación de cada uno de los lugares cerrados apuntados:

- La casa de Punta Gorda es el lugar de la vida familiar: la relación aburrida con Susana «después de tantos años de casado» (p. 31); los escasos encuentros con Gustavo, por la mañana, que no logran disipar «una formidable ignorancia del otro» (p. 94); las visitas episódicas del padre, Edmundo, o del hermano, Hugo (p. 109 y 95). Cuando Ramón describe el estudio de Punta Gorda, insiste en las nociones de confort y rutina:

Cuando pienso que mi vida es gris, tediosa y rutinaria, no se me escapa que la rutina incluye una serie de cosas insignificantes, pero agradables. $\mathrm{Si}$ yo fuera un hombre genial, o poderoso, o simplemente enamorado, tales cosas no tendrían importancia, porque lo importante sería mi obra de arte, o el ejercicio de mi poder, o la plenitud de mi amor, pero como no es ése mi caso, las cosas insignificantes pero agradables pasan a ser estímulos de primer grado. A saber: el auto, mi estudio aquí en Punta Gorda, con buena bi- 
blioteca y vista al mar; este cuarto de baño, verde y negro, con poderosas canillas y un gran grifo mezclador y la bañera opulenta de curvas llenas y femeninas, una bañera que podria haber sido pintada por Matisse; mis camisas impecables, mis trajes bien planchados, mis corbatas de seda natural; los cuadros del estudio y del living, Sposito, Lima, Gamarra, Frasconi, Barcala, Espinola; los dos whiskicitos antes de la cena; la terraza del fondo, con esa paz increible de alguna noche de verano; mi equipo estereofónico, con buenos tangos, buenos blues y buen Mozart; la Rolleiflex y su linda valijita con filtros y accesorios que nunca uso; los libros artísticos de Skira; el juego de cubiertos suecos. Me gusta estar rodeado de cosas lindas (p. 173-174).

A pesar del valor claramente disfórico atribuido a la familia en la obra, la descripción del apartamento revela unos rasgos propios de la personalidad de Ramón (sensibilidad, capacidad imaginativa) que se añaden a los elementos materiales (el confort) y constituyen los vínculos que lo unen a ese espacio de la vida familiar del que quisiera desprenderse.

- La agencia de viajes: es el lugar profesional que debería, teóricamente, marcar la independencia de Ramón, ganada por su trabajo, y que podría simbolizar además la evasión (el viaje). En realidad, esa agencia ha sido fundada por Ramón gracias a los 80.000 pesos que su padre le prestó, y que Ramón le va devolviendo cada año. Como se lo recuerda Edmundo:

Fui yo, con mi plata suciamente ganada, quien te dio la oportunidad que otros no tienen. No importa que me devuelvas el dinero. El hecho sigue siendo el mismo. Vos, y tu mujer, y Gustavo, disfrutan de una posición económica y social que, en honor a la verdad, no puede considerarse estrecha. Pero esa linda posición se debe pura y exclusivamente a que yo, el Viejo cretino y deshonesto, te di a vos ochenta mil pesos suciamente habidos. Dentro de dos años, antes quizá, me habrás devuelto todo el dinero, pero con ello no habrás borrado ni eliminado ese lanzamiento excepcional que te brindó mi préstamo (p. 156).

Lejos de significar la independencia, la agencia de viajes marca pues la eterna, imborrable dependencia de Ramón hacia su padre.

-El despacho del padre: escenario de varias escenas violentas entre Ramón y Edmundo, es otro lugar, a la vez profesional y familiar, que subraya la dependencia de Ramón, el espacio de la enajenación por excelencia. El hecho que el suicidio de Ramón ocurra en este lugar es desde este punto de vista muy revelador.

-El apartamento de las Tres Jotas, donde se desarrollan las dos escenas de amor con Dolly y Marcela, representa, frente a los demás lugares, la evasión de la rutina diaria, familiar y sexual. Pero el hecho que el apartamento no pertenezca a Ramón y le haya sido sólo prestado 
por unos amigos (por lo contrario la amueblada en que vive Gloria pertenece a Edmundo) indica claramente que esta evasión es fortuita: estos dos momentos felices, sin porvenir, que Ramón conoce aquí no podrán impedir su fracaso.

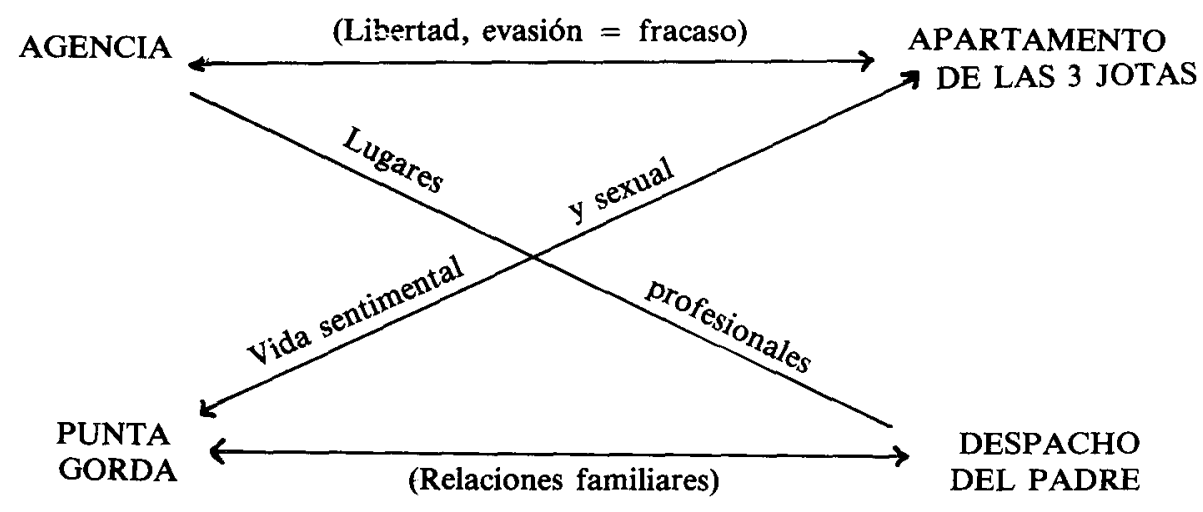

En este esquema del espacio de Ramón en el presente, el eje de los contrarios opone Punta Gorda a las Tres Jotas (valores familiares, moral burguesa VS relaciones prohibidas). Los ejes subalternos enlazan Punta Gorda con el despacho del padre (relaciones familiares) y la agencia de viajes con las Tres Jotas (libertad, evasión fracasada). Este fracaso de los intentos de evasión de Ramón conduce a su suicidio: encerrado en la dependencia familiar y económica dibujada por el triángulo Punta Gorda-Agencia-despacho del padre, que representa el espacio de su enajenación, Ramón, como se lo dice Edmundo (p. 157) no tiene escapatoria. El hecho que el suicidio se verifique desde la ventana del despacho del padre (capítulo 13, p. 274), o sea el mismo lugar en que empezó la crisis de identidad de Ramón (capítulo $2 .^{\circ}$, p. 46), subraya el carácter circular de este espacio, símbolo de la enajenación del protagonista.

\subsubsection{El espacio de Edmundo}

Para Edmundo Budiño, también es preciso distinguir los lugares de actuación en el pasado y en el presente:

-Pasado: la casa de los padres de Inés, la casa familiar, la casa de la tía Olga, la tienda de juguetes, la calle, la Universidad, el viejo Tupí. 
-Presente: el despacho en el diario, el despacho en la fábrica (donde pasa la escena grabada en la cinta y reproducida p. 95-98), la casa de Ramón, la amueblada de Gloria.

La evolución es clara: pasamos de un conjunto diversificado por una alternancia de lugares cerrados y abiertos, profesionales y diversivos, y por un vaivén dinámico del personaje, a un conjunto de cuatro lugares cerrados, profesionales y familiares, que transcriben una evidente esclerosificación del personaje, y que reproducen el mismo esquema que el espacio de Ramón:

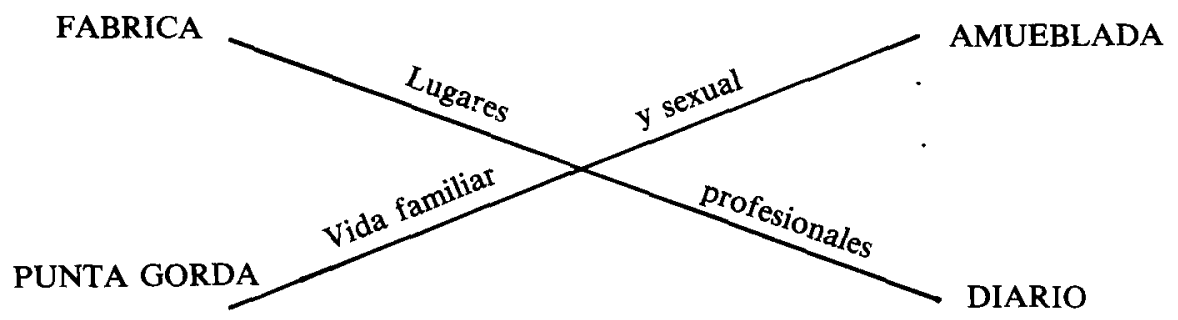

La posibilidad de evasión que podía representar el apartamento de las Tres Jotas para Ramón ni siquiera existe aquí (la amueblada se ha convertido en una especie de espacio familiar, invadido por la rutina): asistimos a una restricción progresiva del espacio de Edmundo, y a su encierro (no sólo simbólico, sino material esta vez) en la amueblada abandonada por Gloria. El portazo con que concluye la novela marca indudablemente el fracaso de Edmundo.

Por lo contrario, Gloria Caselli, que antes de conocer a Edmundo era una joven activa, dinámica, a quien vemos evolucionando en la Facultad, el Salón Nacional de Bellas Artes y el viejo Tupí, y que luego aparece encerrada en la amueblada durante toda su relación con Edmundo (veinte y dos años), logra escapar hacia un nuevo espacio, exterior, símbolo de libertad.

De la misma manera, después de la muerte de Ramón, Dolly toma conciencia de.su amor por él, y la vemos correr con su coche por la Rambla, adonde la conduce el recuerdo de Ramón, y detenerse a orillas del mar.

A través de la dialéctica lugares cerrados VS lugares abiertos, el texto marca así, al nivel espacial, el significado de la trayectoria de los personajes: el encierro (la derrota) o la evasión (la libertad). 


\subsection{El simbolismo ideológico}

El análisis de las funciones que tienen los diferentes lugares de la acción para los principales personajes permite proponer una interpretación del espacio en la novela, que corresponde a ese «symbole idéologique subsumant le tout» de que habla Mitterand ${ }^{13}$.

El primer resultado de nuestro análisis es la puesta en evidencia de la importancia del encierro en el espacio de la novela, marcado por:

-El predominio, cada vez más fuerte en la historia, de los lugares cerrados, hasta el portazo final.

- La circularidad de la estructura textual misma del relato de la historia de Ramón (principio del capítulo 2-final del capítulo 13).

Estos lugares cerrados corresponden a un conjunto de instancias que representan verdaderos centros de poder, o Aparatos Ideológicos del Estado:

-Poder económico (la fábrica).

-A.I.E. informativo y político (el diario).

-A.I.E. familiar (el más recurrente en la obra, el que tiene el papel esencial en la crisis de identidad de Ramón y en su suicidio).

-A.I. E. educativo.

-A. I. E. religioso, etc...

A través de los diferentes puntos de este sistema espacial, es el poder de las clases burguesas, son sus intrumentos de presión sobre los individuos los que están denunciados en la obra. Encerrados en este espacio ficticio, privados de toda libertad, de toda posibilidad de acción, los personajes (Ramón, Dolly, Gloria, pero también finalmente Edmundo) están sometidos a la rutina de una vida sin esperanza, condenados a vivir sin posibilidad alguna de evasión. La rebelión de Ramón contra los mecanismos de poder de su propia clase está condenada de antemano al fracaso. Su suicidio, en cambio, es un hecho imprevisto, minúsculo, una chispa que puede amenazar todo el sistema, si el fuego encendido por Ramón se propaga a los demás personajes, como lo sugiere el título. 
Al nivel colectivo, la ciudad sin nombre (¿símbolo de la pérdida de identidad colectiva de los uruguayos?) está dominada por los valores degradados del dinero, de la fuerza, de la ley injusta que aplasta a los débiles.

Sin embargo, frente a esta estructura del encierro que domina todo el espacio novelesco, hay que subrayar la recurrencia de unos signos que remiten a espacios abiertos, y en particular la presencia tan frecuente del mar:

- La escena del primer amor con Rosario, en la playa de Portezuelo (p. 105).

-La alusión repetida al mar al hablar de la Rambla (p. 171, 240, etc...).

- La escena en que Ramón está «echado sobre una roca, mirando el mar» (p. 58).

-El estudio de Punta Gorda, «con vista al mar» (p. 174). tulo 14).

- Las diferentes alusiones al mar en los recuerdos de Dolly (capí-

Esta presencia del mar podrá, en algunos casos, ser interpretada como la expresión del deseo de evasión de Ramón. Pero su recurrencia inscribe en el sistema espacial de la obra, al nivel simbólico, los valores femeninos, sentimentales y maternales del agua (las estructuras míticas de Gilbert Durand) ${ }^{14}$, que se oponen a los antivalores heroicos, paternales, de la Ley.

A lo largo de la novela, a través del recuerdo obsesionante del dolor de la madre, «mamá dice: Sufro» (p. 93), «y de pronto la mano de mamá se clavó, me clava las uñas en la mejilla» (p. 94), que infunde en Ramón un sentimiento de culpabilidad, asistimos a una búsqueda de la imagen de la madre y un proceso de recuperación de los valores maternales en contra de la omnipotencia de los valores paternales. Este proceso conduce a la fusión desesperanzada de las dos imágenes de Inés, la madre, y de Dolly, la mujer querida, en el último monólogo interior de Ramón, a punto de suicidarse: «Dolores, mi Dolores de otro, si yo también pudiera clavar mis uñas en su mejilla» (p. 274).

G. Durand, Les structures anthropologiques de l'imaginaire, Paris, Bordas, 1969, p. 307. 
El simbolismo del mar introduce así en la novela un conjunto de valores antitéticos del orden burgués:

\section{Poder burgués}

Fuerza

Encierro .

Aislamiento
VS

Simbolismo del mar

Amor

Evasión

Fusión

Será este sistema el que será necesario interpretar en el momento de proponer una lectura sociocrítica de la novela.

\section{La temporalidad narrativa en Gracias por el fuego.}

Siguiendo el esquema trazado por Genette en Figures III, estudiaré tres niveles en el discurso del relato sobre el tiempo: orden, duración y frecuencia.

\subsection{El orden}

Gracias por el Fuego se presenta como el relato cronológico en presente de una historia que empieza en un restaurante de Nueva York y se termina con la muerte de Ramón Budiño (capítulo 13) y la ruptura entre su padre, Edmundo, y Gloria Caselli (capítulo 15). La acción es muy reducida: el único acto verdadero que el protagonista decide hacer - matar a su padre- fracasa, y Ramón se suicida. El presente de la acción se reduce a los menudos hechos de la vida diaria: Ramón se levanta, toma una ducha, se desayuna, va a su trabajo, recibe a sus clientes, regresa a su casa, se acuesta, etc... Una palabra recurrente sirve para caracterizar esta vida: la rutina. Rutina en su relación sexual con su mujer («La rutina se vuelve inevitable [...] El problema es el envilecimiento de la rutina», p. 53), rutina de toda su vida, hasta tal punto que el acto de matar a su padre le aparece como «el final de una rutina» (p. 241).

Las únicas acciones con las que Ramón trata en vano de romper esa rutina son las dos escenas de amor con su cuñada Dolly, y con la que fue su vecina en el restaurante de Nueva York, Marcela Torres de Solís. 
La misma rutina la encontramos en la relación (que dura desde hace veinte y dos años) entre Edmundo y su amante, Gloria.

Gracias por el fuego es todo lo contrario de una novela de acción. Lo que importa es la vida interior de los personajes, son sus recuerdos y sus proyectos.

\subsubsection{Las analepsis}

Las analepsis son muy numerosas. Diferenciaremos las analepsis internas (posteriores a la cena en el restaurante Tequila) y las analepsis externas (anteriores a esta cena, que representa el punto cero del relato).

- Las analepsis internas: algunos ejemplos:

-Ramón recuerda la escena de amor del jueves precedente con Susana (p. 53), el muerto que vio en la Rambla la semana precedente (p. 55), la cena en el Tequila (p. 176).

- La nieta de Ríos recuerda algunos momentos de su viaje a Europa con su abuelo (p. 237).

-Ramón y Dolly recuerdan su única escena de amor (p. 250 y 276).

$\mathrm{Si}$ algunas de estas analepsis tienen una función completiva y permiten llenar un vacío dejado por el relato (p. 53, 55, 237), otras tienen una función claramente repetitiva y sirven para poner el énfasis en unos acontecimientos particularmente importantes, ya narrados anteriormente (p. 176, 250, 276): estamos aquí ante fenómenos de frecuencia, a los que volveremos más adelante.

- Las analepsis externas son las más numerosas. Para ordenarlas, las clasificaremos en seis grupos:

a) Los recuerdos de infancia de Ramón: la escena en la tienda de juguetes, cuando Ramón tiene seis años (p. 48-50), la muerte de su primo Víctor (Ramón tiene ocho años, p. 55), la conversación entre los padres y la decisión de mandarlo al colegio alemán (siete años, p. 58), su padre viene a tranquilizarlo cuando tiene miedo de noche (p. 59-60), los carnavales de antes y su amigo Angel (once años, p. 63), la iglesia de Punta Carretas y la comunión (once-doce años, p. 72), el colegio alemán y Herr Hauptmann (p. 81-85), el miedo más antiguo de Ramón (seis años, p. 170), Ramón hiere a Víctor (p. 221-222), Ramón y las mon- 
jas (seis años, p. 248). Vemos que si las seis analepsis narradas siguen prácticamente el orden cronológico (de seis a doce años), las cuatro siguientes tienden a invertir este orden, para regresar a la edad del primer recuerdo (seis años).

b) Los recuerdos de adolescencia y juventud de Ramón: tres episodios importantes corresponden a ese período de la vida de Ramón: el primer amor con Rosario, a los diecisiete años (p. 105-108), la húngara y la escena del tren (p. 148) y la estancia en Buenos Aires (veintiún años) (p. 203).

c) Los recuerdos más recientes de Ramón: la estancia en Estados Unidos (p. 69-71) y en San Francisco (p. 167), el diálogo a solas con Dolly en una fiesta de fin de año (p. 101).

d) Los recuerdos relativos a los padres de Ramón: la escena más importante es la que se desarrolla detrás de la mampara, en la cual Edmundo pega a su mujer Inés (p. 77), pero también tenemos en este grupo: los primeros tiempos de las relaciones entre Edmundo e Inés, antes de su casamiento (recuerdos de la tía Olga, p. 87), la muerte de Inés (p. 91-94), la actitud del padre durante la huelga de los obreros de su fábrica (p. 196).

e) Los recuerdos de Edmundo y Gloria: ocupan prácticamente todo el capítulo 7 de la novela, que nos cuenta cómo Gloria vino a ser la amante de su profesor, Edmundo (p. 116-120) y cómo evolucionaron las relaciones entre Gloria y Edmundo desde 1939 hasta 1961 (p. 123-124). Este último tema ocupa también parte del capítulo 15 (p. 284-290).

Estas analepsis tienen una estructura profundamente distinta de las precedentes: mientras Ramón recuerda siempre una escena precisa, Gloria hace un como balance de su vida con Edmundo, en un verdadero relato sumario ${ }^{15}$.

f) Los recuerdos de Dolly: desde su niñez (p. 276) hasta la muerte de Ramón (p. 278).

Este inventario, limitado a las principales analepsis, muestra la importancia del pasado, que invade sin cesar el presente de la historia, instaurando un continuo vaivén pasado-presente.

15 Traduzco por relato sumario la expresión de Genette récit sommaire tomada del inglés summary. 


\subsubsection{Los mecanismos de transición presente-pasado y la actualización del pasado}

El paso del presente de la acción al pasado se realiza en el texto según tres modalidades distintas:

a) La transición indirecta por el verbo recordar ( o acordarse) es la manera más común de evocar una escena pasada, que encontramos utilizada varias veces en el texto:

- «Nos acordábamos de aquel bruto trompazo que te dio Herr Hauptmann. ¿Te acordás?» (p. 80).

- «Ahora que estoy vieja y reumática y el pobre Esteban se me fue y ya casi no me acuerdo de cómo era la carita de Víctor, mi nene querido.» (p. 87).

— «Ah, me acuerdo que aquella noche estaba el chico de Martín Salas.» (p. 87).

- ¿Por qué será que siempre, cuando me despierto en la madrugada, casi el único recuerdo que comparece es el de la primera vez?» (p. 105), etc...

b) La transición por asociación: una palabra, una visión, un sentimiento, un sabor bastan para hacer resurgir en la mente de Ramón toda una escena del pasado. El mejor ejemplo de este mecanismo de transición es la tostada del desayuno que tiene gusto a hostia (p. 72), introduciendo así el recuerdo de la comunión en la iglesia del pueblo de su niñez. Otro ejemplo: cuando Ramón decide matar a su padre, se pregunta: ¿Cómo será eso de matar?» y recuerda un episodio de su niñez, cuando creyó haber matado por accidente a su primo Víctor (p. 221).

De la misma manera, una interrogación sobre el miedo («¿Será cierto que los héroes tienen miedo?») provoca un nuevo esfuerzo de memoria para evocar «el más antiguo de mis miedos» (p. 169).

c) El paso directo del presente al pasado, sin transición: esta modalidad original aparece varias veces en el relato (p. 48, 55, 58, 63, 77, $91,100,148$, etc...). Tomemos el ejemplo de la secuencia de las páginas 58-60. Ramón está a orillas del mar: «Siempre me ha gustado estar como ahora estoy. Echado sobre una roca, mirando el mar... Miraré el cielo, mejor. Ni una gaviota. Las sábanas estaban frías. Allá arriba el techo, altísimo, manchado, inalcanzable. La lamparilla pendía, inmó- 
vil, de un largo cordón, cinco moscas. Siete años, ché, había dicho tía Olga...»

Hay en el texto una identificación entre el cielo que Ramón está contemplando y el techo («altísimo...inalcanzable») de la habitación de su niñez: a partir de este simple elemento surge el recuerdo preciso de una escena penosa del pasado, cuando su padre decidió mandarlo al colegio alemán.

Muchas veces, en estas evocaciones del pasado, la escena resucitada está puesta de relieve por un procedimiento de actualización y elipsis de las marcas temporales. Es lo que ocurre, por ejemplo, en la escena de la tienda de juguetes («en lo de Oddone», p. 48-50). Partimos, aquí también, de una imagen concreta del presente para remontarnos a un pasado remoto, evocado primero en imperfecto y pretérito:

«¿Qué hace esa paloma baja la lluvia? Le pesa caminar. ¿Tan atrás, tan atrás? Debe hacer de esto por lo menos treinta y cinco, treinta y seis años. No: justo treinta y cinco. Todavía no era el Viejo. Sólo Papá... Elige el juguete que quieres, dijo Papá».

De repente, este pasado se convierte en presente, por repetición del mismo verbo y sustitución de tiempo:

«Alcé lentamente los ojos... Había, hay un hombre detrás del mostrador».

A partir de este momento, el personaje vuelve a vivir la escena pasada como si fuera presente. Gracias a la utilización conjunta del presente de narración y del estilo directo, reforzada aqui por la creación de una voz infantil, distinta de la del narrador ( «Lo digo en mi media lengua», «¿Poqué paleco una homiga?»), se logra durante un momento una elipsis casi total de la figura del narrador, y se crea la ilusión tan difícil de una visión infantil: todo pasa como si viviéramos directamente la escena a través de la mirada y del relato del niño («Todavía no era el Viejo. sólo Papá. Papá dicho y pensado minuciosamente a mis seis años.»

Pero la perspectiva actual (el presente de la enunciación que corresponde al narrador-actor adulto) vuelve a aparecer en algunos segmentos de reflexión sobre el pasado, como:

«Es probable que haya dicho...» 
«Pero a esa altura mi media lengua no es totalmente sincera», hasta que al final el presente de narración cede ante el pasado:

«Es lindo ir caminando con Papá. No hubiera podido decirlo con palabras, pero me sentía protegido, contento. Era estupendo saberse hijo de ese tipo impecable, elegante, siempre afeitado...»

A través de este procedimiento de actualización del pasado, asistimos en varias páginas de la novela a un intento, valioso desde el punto de vista técnico, de recreación de una visión infantil, que traduce una voluntad de idealización del pasado, que se manifiesta también por otros procedimientos, como la búsqueda del recuerdo original.

\subsubsection{El recuerdo original y la exaltación de un pasado mítico}

Es notable la recurrencia en la obra del tema del recuerdo original, subrayado por el adjetivo «primero» o la expresión «la primera vez». Citemos algunos ejemplos:

-p. 55: «El primer muerto que vi no era repugnante. Prefiero aquel primer muerto.»

-p. 105: «¿Por qué será que siempre, cuando me despierto en la madrugada, casi el único recuerdo que comparece es el de la primera vez?»

-p. 116: «el primer elogio de Edmundo...»

-p. 119: «Cuando la llevó por primera vez a la amueblada...»

-P. 247: «la primera vez que le pegué...»

-p. 276: «Cuando en los tiempos de la primera regla, yo cerraba violentamente los ojos... y cuando por primera vez vi un hombre desnudo...»

—p. 194: «la única vez que ejercité la pesca...»

Esta importancia otorgada al recuerdo original confiere al pasado una calidad peculiar de pureza que resalta en el recuerdo del primer amor de Ramón: Rosario (p. 105-108).

En contra de la imagen negativa de la infancia y la adolescencia que tanto se da en la literatura desde Freud, y que encontramos a la vez en la novela europea (Sartre, Nizan) y en la novela latinoamericana (pensamos en particular en La ciudad y los perros, que utiliza como epígrafe esta frase del Aden Arabie de Nizan: «J'avais vingt ans. Je ne lais- 
serai personne dire que c'est le plus bel âge de la vie»), que se esfuerzan por desbaratar el antiguo mito de la inocencia de la juventud, este texto exalta la adolescencia como un estado de inocencia prolongada. La inexperiencia, la ignorancia (subrayadas por expresiones como sin pericia, inexpertos, no sabemos, no tenemos idea de qué, yo no sé nada, la primera vez) están marcadas aquí positivamente por todo el campo semántico de la alegría, la plenitud: lo bueno (2 ocurrencias), lindo (2), lindísimo, delicioso, ideal, magnífico, estupendo, contentos, contenta, agradecida, alegría (2), verdadera comunión, perfecta comunión, plenitud. Esta plenitud alcanza una dimensión religiosa con la repetición de comunión, y el uso de unción, Por Dios, Dios mío: «Me pareció un acto de verdadera y excepcional unción que ella usara diosmío como una mera interjección de placer».

A este campo semántico de la plenitud, de signo positivo, se opone otro de signo negativo, el del tedio, de la tradición, de la moral falluta: púdica, temerosa y avergonzada, autorizado, normas, patética, amor eterno, sentimental, conmovedor. De la misma manera, a la imagen de Rosario nuevita e inocente, se opone la de «la respetable señora del doctor Azócar, con tres hijos crecidos, dos sirvientes y un chalet en Carrasco». A través de expresiones como es tan natural o Estamos más acá del Bien y del $\mathrm{Mal}^{4}$, el pasado adquiere aquí un valor mítico: es el tiempo primitivo, el tiempo del origen, que corresponde al paraíso perdido (notemos que la soledad, los árboles y el estado de desnudez de los protagonistas son signos evidentemente edénicos).

\subsubsection{Las prolepsis}

Mucho menos numerosas que las analepsis, las prolepsis son de dos tipos:

- Las que anuncian hechos triviales que pertenecen a la rutina de la vida diaria. Por ejemplo, Ramón regresa de la agencia en su coche y piensa en lo que va a decirle Susana a su llegada: «Seguramente vendrá Susana a contarme los chismes de Laura o a quejarse de lo cansada que está debido a que se ha quedado sin muchacha... o, lo peor de todo, a sugerirme que hoy vayamos a cenar a Carrasco, porque no está como para ponerse a cocinar»; (p. 219) y Susana lo acoge diciéndole: «Vine aquí a esperarte para que no entres el auto al garaje. Estoy tan cansada ahora que no tengo muchacha que, francamente, no tengo ganas de cocinar. ¿Qué te parece si vamos a cenar a Carrasco?» (p. 220). 
De la misma manera, Gloria, que espera la llegada de Edmundo, sabe de antemano todos los gestos que hará, todas las palabras que dirá.

- Las que anuncian la muerte de Edmundo, que corresponde al proyecto frustrado de Ramón: desde la visión que el mismo Edmundo tiene de Ramón apuntándole con el revólver (p. 128) hasta los artículos de los periódicos que anunciarán la muerte del Prócer, imaginados por Ramón (p. 188). En este caso, la prolepsis no es más que una falsa pista que hace todavía más rotundo el fracaso de Ramón, su incapacidad para actuar, para cometer ese acto que le daría la deseada libertad y le permitiría enfrentar el porvenir.

Finalmente, lo que caracteriza el sistema temporal de la novela, con la inexistencia de auténticas prolepsis, es la ausencia de un futuro verdadero para los personajes de la historia, confirmada en los dos últimos capítulos que tienen una función de epílogo: Dolly que con la muerte de Ramón ha perdido a su amante y al mismo tiempo a su esposo (ya que se da cuenta de que nunca podrá querer más a Hugo) se califica como una hembra destruida (p. 280), y Edmundo aparece por primera vez a los ojos de Gloria como un viejo vencido, doblado, caviloso ( $\mathrm{p}$. 284). Sólo Gloria y Gustavo pueden encarnar, al cerrarse la novela, un hipotético porvenir.

Esta ausencia de la dimensión del futuro en la novela se opone a la hipertrofia del pasado que lo invade y lo domina todo.

\subsection{Duración}

La duración de la historia es fácil de precisar gracias a las indicaciones precisas integradas al relato. $\mathrm{La}$ escena en el restaurante Tequila (punto cero del relato) lleva una fecha: «Ha entrado la noche en un viernes de abril de 1959».

Entre este capítulo primero, que opera como un detonador que causará la crisis de identidad de Ramón y la toma de conciencia de su enajenación, y los catorce capítulos siguientes, una elipsis implícita nos hace dar un salto de dos años. En efecto, en el capítulo 7, Gloria evoca el día que marcó su vida, cuando Edmundo le pidió que fuera su amante: el 10 de septiembre de 1939 (p. 116) y el texto prosigue: «Todavía hoy, veinte y dos años más tarde, la cara del espejo se sonroja» (p. 119) (o sea que hoy es 1961). 
Esta elipis de dos años está confirmada varias veces: Ramón dice a Marcela en el capítulo 1 y que tiene un hijo de quince años (p. 31), y en el segundo (p. 47) afirma que Gustavo tiene diecisiete (p. 47).

Cuando Ramón encuentra de nuevo a Marcela, calcula: «En el 59, tenía 23 , así que tendrá 25.»

Ahora bien, ¿qué tiempo transcurre entre el capítulo 2 y el final de la novela? A principios del capítulo $2 .^{\circ}$, Ramón está pensando ante la ventana abierta del despacho de su padre (p. 46). En el capítulo 13, lo encontramos en la misma situación, decidido a matar a su padre: «Aquí mismo, hace unos cuantos meses, pensé...»

Los dos últimos capítulos, destinados a mostrarnos los efectos del suicidio de Ramón sobre Dolly y el Viejo, suceden días después. De modo que la acción principal (capítulo 2 al 15) dura apenas algunos meses, o sea, el tiempo de la crisis de identidad de Ramón y su muerte. Si la escasez de acontecimientos da la impresión al lector de que el tiempo no ha transcurrido, las múltiples analepsis alargan mucho la duración de la historia narrada: a través de los recuerdos de la infancia de Ramón y de la juventud de Gloria, y hasta la juventud de Edmundo e Inés, es un período de unos cuarenta y cinco años de la vida de los protagonistas el que está reconstruido progresivamente.

En esa reconstrucción, es de notar la importancia otorgada a algunas fechas precisas del pasado. Ya señalamos la fecha de la cena en el restaurante Tequila (viernes de abril de 1959). Pero también encontramos:

-p. 63: «Mamá me había dado diez pesos. Diez pesos en 1928.»

-p. 101: «Faltaban quince minutos para el Primero de enero de 1957».

-p. 108: «aquella tarde de febrero de 1934».

-p. 116: «Así me había dicho Edmundo Budiño el 10 de septiembre de 1939».

-p. 118: «Primer segmento: desde el 4 de diciembre de 1920 hasta el 10 de septiembre de 1939. Segundo segmento: desde el 10 de septiembre de 1939 hasta hoy. Estas fechas precisas subrayan la importancia concedida por los personajes (Ramón, Gloria) a algunos momentos de su pasado: escena de amor de Ramón y Rosario, conversación a solas con Dolly, o primer elogio de Edmundo. Otra manera (y un signo más) de marcar la trascendencia de algunos recuerdos originales. 


\subsection{Frecuencia}

Lo que caracteriza el relato de la vida de Ramón es la repetición de unas mismas escenas: el desayuno con Susana (capitulo 4) o con Gustavo (capítulo 8); las conversaciones con su secretaria, los clientes de la agencia de viajes (capítulos $2,5,9,18$ ) o con su padre (capítulos 4 , 9), los trayectos de ida y vuelta desde el apartamento de Punta Gorda hasta el centro de la ciudad. Así queda fuertemente marcado el carácter de «rutina» de esa vida, denunciado por el protagonista.

Para precisar el estudio de los fenómenos de frecuencia en la obra, podemos distinguir los segmentos iterativos de los segmentos repetitivos:

- Hablaremos de iteración (siguiendo a Genette) cuando el texto alude una vez (o unas pocas veces) a una escena que ocurrió muchas veces: por ejemplo la escena en que el padre viene a tranquilizar a Ramón niño, cuando tiene miedo, por la noche, en su cama, recordada tanto por Ramón (p. 60, 255) como por Edmundo (p. 291).

-Más frecuentes son los fenómenos de repetición que consisten en aludir varias veces a un acontecimiento que ocurrió una sola vez, por ejemplo:

-La escena en la juguetería (en lo de Oddone) (p. 48-50, 255, 291).

-El muerto en la Rambla (p. 55, 147).

-La muerte de Víctor (p. 55, 255).

-El episodio de Rosario (p. 105-18, 151, 163).

-El dolor de la madre (p. 77, 91, 92, 93, 94, 273, 274).

Estos ejemplos ponen de relieve el carácter fuertemente repetitivo del relato en Gracias por el Fuego: algunos acontecimientos del pasado, felices (la escena en la juguetería, Rosario), o infelices (la muerte de Víctor, el dolor de la madre) vuelven de modo cíclico, obsesionante, a atormentar al protagonista. Incapaces de actuar, totalmente volcados hacia el pasado, los personajes de la novela (Ramón en particular) no parecen creer en la posibilidad de un acto nuevo: se contentan con tratar de rescatar o reactualizar, dichosa o dolorosamente, los acontecimientos ya vividos.

Ramón, por ejemplo, busca a través de todas las mujeres que encuentra la felicidad perfecta que conoció la primera vez con Rosario, idealizada en su recuerdo original, al mismo tiempo que la imagen des- 
garradora del sufrimiento de su madre. Y su amor a Dolly se funda en la conjunción de esa doble imagen de la mujer.

Por más paradójico que parezca, a primera vista, tratándose de una novela $\tan$ fuertemente anclada en la circunstancia actual uruguaya, este tiempo cíclico tan importante en la obra, que se repite eternamente sin que surja ningún acontecimiento nuevo, se relaciona con el tiempo mítico del eterno retorno, analizado por Mircea Eliade.

\section{Conclusión: lectura sociocrítica de la novela}

El presupuesto metodológico fundamental del C. E. R.S. (Centro de Estudios e Investigación Sociocrítica de Montpellier) consiste en analizar la estructura profunda de los textos, y tratar de mostrar cómo las estructuras de sociedad están inscritas directamente en ellas. Para proponer una lectura sociocrítica de Gracias por el fuego intentaré definir brevemente las estructuras de sociedad que se relacionan con la obra de Mario Benedetti.

La característica esencial de la formación social uruguaya contemporánea, tal como aparece descrita por los historiadores y sociólogos de ese país ${ }^{16}$, es la aparición precoz, mucho más precoz que en los demás países de América latina, de una pequeña burguesía urbana (montevideana) de funcionarios y empleados, producida por la política de nacionalizaciones y desarrollo del sector público de José Batlle y Ordóñez y sus sucesores. (1904-1929). Esta burguesía es la principal beneficiaria de la legislación social (protección de los trabajadores, jubilación, vacaciones) y escolar (gratuidad y laicidad de la enseñanza) del período batllista. El alto nivel económico y social alcanzado por la población uruguaya en la primera mitad de este siglo (Uruguay era en 1950 el país de América latina con la tasa más alta de niños de hasta quince años escolarizados) explica el nacimiento dentro de esta población de cierto orgullo de ser uruguayo (expresado por el lema Como el Uruguay, no hay) y la aparición rápida de una conciencia nacional en un país constituido mayoritariamente por inmigrantes recién llegados de Europa. Ex-

16 Véanse en particular:

L. C. Bevenuto (y otros), Uruguay hoy, Buenos Aires, Siglo XXI, 1971.

Carlos Rama, Historia social del pueblo uruguayo, Montevideo, Comunidad del Sur, 1972.

Carlos Rama, Uruguay en crisis, Montevideo, El Siglo Ilustrado, 1969. 
plican también la fidelidad de la clase media uruguaya, hasta 1958 y aún más tarde, al viejo partido colorado, que le parecía encarnar el mito de la prosperidad del país, a pesar de la crisis y de la falta evidente de imaginación de sus dirigentes, incapaces de promover las reformas necesarias para el mantenimiento de esa prosperidad.

Pero en esta pequeña burguesía instruida había nacido una generación de intelectuales que empezaron, en los años de 1939-1940, a desarrollar una reflexión crítica original por su libertad, porque contemplaba todos los aspectos de la vida política, social y cultural del país, permaneciendo al margen de los diferentes partidos políticos. Es lo que se suele llamar la generación crítica, que alcanza su expresión más acabada en el semanario Marcha, fundado en 1939 por Carlos Quijano, en el que Angel Rama ve «la asunción de la conciencia crítica)» ${ }^{17}$. Esos intelectuales expresan, antes que todo, su insatisfacción ante el inmovilismo, la esclerosis, el envejecimiento de las estructuras del país, tan opuestos al dinamismo de la edad de oro batllista, y denuncian la vanidad de los políticos de los años de 1940 a 1960 , la vacuidad de su discurso político, los peligros que amenazan el país desde fuera (en particular, el imperialismo norteamericano). Este discurso crítico desarrollado entre 1940 y 1970 constituye una práctica discursiva fundada en una práctica social original, que tiene sus raíces en la situación histórica peculiar de un grupo de intelectuales que se hallan en contradicción con su clase de origen, a la que no dejan de dirigirse sin embargo lo más directamente posible, a través de todos los medios de expresión de que disponen: prensa, novela, cuento, poesía, teatro, artes. Es la influencia de este discurso de la generación crítica la que explica la permanencia de la problemática nacional en la producción cultural uruguaya de esos años 1940-1970, que constituye un rasgo original de la novelística de Mario Benedetti, comparada, por ejemplo, con las obras publicadas en los mismos años en los países vecinos.

Periodista, ensayista (miembro activo del equipo de Marcha y autor de un ensayo crítico, El país de la cola de paja, que es una crítica aguda de la vida política uruguaya, y que tuvo un enorme éxito), Mario Benedetti aparece como una de las figuras más eminentes de la generación crítica. No es sorprendente pues encontrar en sus novelas, entre ellas en Gracias por el fuego, unos segmentos textuales que parecen salir di-

17 Angel Rama, La generación crítica (1939-1969), Montevideo, Arca, 1972, p. 89. 
rectamente de los ensayos publicados por los miembros de la generación crítica. Por ejemplo el diálogo del capítulo 6 en que Gustavo opone la edad de oro batllista al presente: «Convénzase, abuelo, dijo Gustavo. Los partidos tradicionales están en vía de descomposición. ¿Dónde están Batlle, Saravia, Brum? Todos bajo tierra. Allí también están sus respectivos idearios: bajo tierra.» (p. 109).

O también el diálogo del capítulo 8 entre Ramón y Gustavo (p. 133-138), que insiste sobre la corrupción de los políticos y la primacía de lo moral sobre lo económico.

Pero, fuera de esas similitudes cuyo inventario se podría alargar mucho, lo que me interesa mostrar es que el sistema espacio-temporal, que ha caracterizado en las dos primeras partes de este trabajo, es el mismo que rige el discurso de la generación crítica.

Angel Rama define así la conciencia crítica:

La conciencia crítica no puede medirse válidamente sino en su enfrentamiento con los valores dominantes, ya que es una típica posición adversativa. Contra la exaltación engañosa que aún se prolongaba respondiendo al populismo batllista instala la depresión esquiva y desdeñosa, lo que vale como oponer al júbilo que fuera estrepitoso en los años locos, el miedo que trepó los cuarenta, y a la coparticipación alegre con el mundo que se vivió en la década rosada del progresismo antifascista, la melancolía, la tristeza, el presentimiento de lo mortal... Contra el idealismo terca y fraudulentamente anclado en el futuro que cree contemplar desde lo alto de la ola contemporánea, opuso la inserción en el tiempo, el fluir de la vida, la historia como obsesión, la recuperación del pasado como necesidad de interrogación a las raíces, el sentimiento de la inseguridad y precariedad de la existencia ${ }^{18}$.

Casi todas las características atribuidas por Angel Rama a la conciencia critica pueden aplicarse a Gracias por el Fuego: enfrentamiento con los valores dominantes, típica posición adversativa, melancolía, tristeza, presentimiento de lo mortal, sentimiento de la inseguridad y precariedad de la existencia, etc... Limitándome a los elementos descubiertos a través del análisis de la estructura espacio-temporal de la novela, subrayaré las coincidencias siguientes entre el discurso de la generación crítica y la obra de Mario Benedetti:

-Una misma visión negativa, claramente disfórica, de un presente reducido a una mera rutina desesperanzada. 
- La misma denuncia de los valores dominantes que corresponden en la novela a los Aparatos Ideológicos del Estado burgués

-La misma exaltación (idealización, mitificación) del pasado, con la que podemos relacionar el tema recurrente del regreso al origen inscrito a través del simbolismo del mar y de la búsqueda de la madre.

Esta idealización del pasado en la novela corresponde evidentemente al mito de la edad de oro batllista en el discurso de la generación crítica: no es una casualidad si la niñez de Ramón corresponde a esos felices años veinte en que Uruguay es la Suiza de América latina. En cuanto a la imagen del «Papá» sonriente, protector, justo y generoso que trae la felicidad a todos, podemos preguntarnos si no es una simple transcripción de la imagen mítica del mismo Batlle.

Desde el punto de vista metodológico, la lectura sociocrítica que propongo de la novela de Mario Benedetti se apoya en un intertexto (el discurso de la generación crítica) que, como práctica discursiva, tiene aquí una función de verdadera instancia de mediación entre las estructuras textuales, tales como he podido definirlas a través del estudio de las categorías del espacio y del tiempo, y las estructuras de sociedad, en la medida en que nos remite a una práctica social auténtica y original, que es una característica esencial de la formación social uruguaya contemporánea. 